Revista de E conomia Política, vol. 25, no 2 (98), pp. 101-114, abril-junho/2005

\title{
Regimes cambiais: um modelo alternativo para o Brasil
}

MANOEL CARLOSDE CASTRO PIRES*

Exchange Rate Rules: An Alternative M odel for Brazil.

A bstract: After the collapse of the Bretton W oods system, many frameworks of exchange rate have been proposed. The aim of this paper is to propose an alternative rule of exchange rate and evaluate the case for Brazil. The analysis of the Brazilian case made necessary the evaluation of auxiliary instruments for its implementation. The paper proposes the use of capital controls or scape clauses.

Key words: Exchange R ate Rules, Scape Clauses, Transparency.

JEL Classification: F33, F41.

\section{INTRODUÇÃO}

A trindade impossível, um resultado extraído do modelo $M$ undell-Fleming, afirma que a conjugação das três condições seguintes: a mobilidade de capitais, 0 câmbio fixo e a autonomia para realizar políticas econômicas independentes não representa uma combinação teórica consistente. No caso, uma dessas condições deve ser abandonada para que as outras duas possam vigorar. Durante a primeira parte do sistema de Bretton Woods a opção encontrada foi a exclusão da mobilidade de capitais combinada a um sistema de taxas de câmbio fixas, porém ajustáveis, com a autonomia de políticas econômicas. ${ }^{1}$

Com o aumento da mobilidade de capitais e a conseqüente derrocada do sistema de Bretton W oods, no início dos anos 1970, tornou-se crescente a adoção

\footnotetext{
* Técnico em Pesquisa da Coordenação de Finanças Públicas (CFP) do IPEA e doutorando do IEUFRJ. E-mail: manoel.pires@ipea.gov.br. 0 autor agradece ao professor Francisco Eduardo Pires de Souza e a dois referees pelos profícuos comentários em uma versão anterior deste artigo. Entretanto, erros e omissões são de responsabilidade do autor. [Submetido: novembro, 2003; aceito: junho, 2004]. ${ }^{1}$ D e fato, a partir dos anos 1960, a mobilidade de capitais aumentou até que o regime se tornou insustentável no início dos anos 1970.
} 
de regimes cambiais mais flexíveis por diversos países. A justificativa para esse comportamento se deve ao fato de que tal estrutura não cria os desalinhamentos excessivos (que elevam a inflação, causam desequilíbrios no balanço de pagamentos e alteram as pautas de exportação e importação) de um regime flutuante, e ainda concede algum grau de independência para a realização de políticas econômicas.

Esta foi a alternativa encontrada durante os anos 1980 e o início dos anos 1990 com a experiência do Sistema M onetário Europeu e por grande parte dos países emergentes durante $o$ início dos anos 1990. Estes regimes cambiais, entretanto, foram alvos de ataques especulativos, o que fez com que fossem flexibilizados ou mesmo abandonados. ${ }^{2}$

A partir daí começou-se a identificar uma tendência para regimes extremos como a união monetária (no caso dos países europeus) ou o regime de flutuação cambial (Eichengreen, 1994). Contudo, em algum sentido, a flutuação cambial é inevitável: mesmo a instituição de uma união monetária não a evita, dado que suas relações financeiras e comerciais com os países não membros permanecerá (Eichengreen, Tobin e Wyplosz (1995)).

R ecentemente a tese da flutuação tem sido descartada em razão da descoberta de que países, que se classificam como flutuantes, exibem fear of floating (Reinhart, 2000). A razão para este comportamento se deve ao fato de que estes países não conseguem contrair dívidas e pagá-las em sua própria moeda. $N$ estes termos, qualquer alteração da taxa de câmbio é capaz de agravar o descasamento monetário. Assim, estruturas intermediárias voltam a desempenhar um papel fundamental na política de estabilização macroeconômica.

0 objetivo deste artigo é propor um regime de câmbio intermediário e avaliar suas aplicações ao caso brasileiro. Além disto, a aplicação ao caso brasileiro fez-nos incluir a necessidade de controle de capitais e/ou cláusulas de escape na análise. A lém desta introdução 0 artigo tem mais seis seções. A próxima resgata a clássica análise de Friedman (1953) em favor de regimes flutuantes. A terceira seção discute a análise de W illiamson (2000) em favor de regimes intermediários. Em especial, mostra-se que os argumentos de Friedman (1953) foram vencidos pela alta mobilidade de capitais, uma realidade do mundo atual. A quarta seção propõe o regime, a quinta simula para o caso brasileiro e a sexta discute a necessidade de controle de capitais e/ou cláusulas de escape. Por último, apresentamse as conclusões.

A aplicação ao caso brasileiro nos faz concluir que regimes intermediários se tornam factíveis apenas em estruturas flexíveis em que a autoridade monetária dispõe de instrumentos auxiliares como os controles de capitais e as cláusulas de escape.

\footnotetext{
${ }^{2} \mathrm{~N}$ o caso dos membros do Sistema M onetário Europeu optou-se pela ampliação das bandas cambiais que passaram de $+/-2,25 \%$ para $+/-15 \%$. Em países emergentes a escolha, na maioria dos casos, foi a flutuação cambial, como no M éxico, Brasil, Argentina e alguns países asiáticos.
} 


\section{EM DEFESA DE UM REGIME FLUTUANTE: A ANÁLISE DE FRIEDMAN}

A o analisar as opções de ajuste de um país a uma situação de desequilíbrio no balanço de pagamentos, Friedman (1953) concluiu que a melhor opção seria a adoção de um regime de câmbio flutuante. Sua argumentação se baseia na comparação de quatro opções de ajuste: (i) via ajuste na taxa de câmbio; (ii) via ajuste nos preços internos ou na renda; (iii) via controles diretos; e (iv) por intermédio do uso de reservas.

0 ajuste na taxa de câmbio depende do regime de câmbio utilizado pelo país. $\mathrm{N}$ o caso de um regime flutuante, se o desequilíbrio for visto como temporário, as transações especulativas mantêm o câmbio estável. Se o desequilíbrio for visto como produzido pelos fundamentos, o ajuste se acelerará. Assim, a taxa de câmbio se move "rapidamente, automaticamente e continuamente e então tende a produzir movimentos corretivos antes que tensões possam se acumular e uma crise se desenvolver" (Friedman: 1953, p. 163).

No caso de um regime temporariamente fixo, as transações especulativas têm um efeito diferente. Segundo Friedman (1953), cada alteração na taxa de câmbio torna-se uma oportunidade para a crise. $\mathrm{N}$ ão existem mecanismos que produzam correções na taxa de câmbio. Em verdade, a grande parte dos agentes conhece a direção do ajuste que será tomado e, portanto, existem grandes incentivos para se antecipar, o que torna a transação especulativa altamente instabilizadora.

O ajuste nos preços internos ou na renda pode, em princípio, trazer os mesmos resultados das alterações na taxa de câmbio. ${ }^{3}$ Entretanto, como preços são rígidos em diferentes níveis, 0 ajuste se daria com várias distorções. Em alguns setores, o ajuste dar-se-ia via preços e em outros, via quantidades. Este comportamento criaria uma situação recessiva até o momento em que o ajuste fosse finalizado.

0 ajuste por meio de controles diretos é indesejável, segundo Friedman (1953), porque: (i) interfere na eficiência da distribuição e produção de bens; (ii) torna a moeda doméstica menos desejável porque limitam-se as possibilidades de que seus possuidores a utilizem, (iii) existem várias dificuldades políticas e administrativas para impor e executar tais controles; e (iv) dados suficientes incentivos para fazê-lo, várias formas serão encontradas para a evasão destes controles.

O ajuste via utilização de reservas seria desejável em situações de desequilíbrios temporários. Entretanto, o uso de reservas é pouco eficaz em uma situação de desequilíbrio permanente ou de longa duração. A lém disso, raramente é possível saber se o evento será revertido rapidamente ou não.

\footnotetext{
${ }^{3} \mathrm{~N}$ o caso de preços flexíveis, "faria pouca diferença econômica se os ajustes são realizados via mudanças na taxa de câmbio ou por meio de equivalentes alterações nos preços internos" (Friedman: 1953, p. 165).
} 
O resultado desta análise leva Friedman (1953, p. 158) a concluir que o câmbio flexível é o regime desejável e que ${ }^{4}$ defender tal regime não é equivalente a defender taxas de câmbio instáveis. 0 último objetivo é um mundo no qual taxas de câmbio, enquanto livres para flutuar, são de fato altamente estáveis. Instabilidade das taxas de câmbio é um sintoma de instabilidade na estrutura econômica subjacente.

É interessante notar que os ajustes que Friedman analisa se dão pelas transações correntes, apesar de supor um mundo sem qualquer tipo de controles e, portanto, um mundo com mobilidade plena de capitais. Parece que o autor não havia imaginado que o mercado de capitais pudesse ter tomado a proporção que tomou nos anos recentes. Com a alta mobilidade de capitais, existente no mundo atual, grandes desalinhamentos da taxa de câmbio de equilíbrio têm ocorrido, o que justifica a proposta de regimes intermediários. ${ }^{5}$

\section{EM DEFESA DE UM REGIME INTERMEDIÁRIO: A ANÁLISE DE WILLIAM SON}

W illiamson (2000) analisa algumas novas possibilidades de regimes intermediários. Segundo o autor, estes se justificam porque "repetidas aparições de maiores desalinhamentos nas taxas de câmbio entre as moedas flutuantes têm levado alguns de nós à conviç̧ão de que o problema não foi a forma como as ta$x$ as foram administradas, mas o que aconteceu quando elas não foram administradas" (p. 6).

A própria evidência tem mostrado que a análise de Friedman (1953) estava equivocada: "A evidência mostra que, sob um regime flutuante, uma alteração na taxa à vista é normalmente associada com uma alteração quase idêntica na taxa futura, significando que existe uma falha virtualmente completa de qualquer expectativa de mercado de que a taxa de câmbio se reverta em direção ao nível de equilíbrio dentro de algum horizonte de tempo relevante" (Williamson, 2000, p. 23). ${ }^{6}$

\footnotetext{
${ }^{4}$ Se taxas de câmbio só se movem de acordo com a estrutura econômica subjacente, a manutenção de fundamentos sólidos seria a âncora para o regime de taxas flutuantes. Entretanto, parece ser consenso que as largas flutuações cambiais estão muito pouco relacionadas com mudanças nos fundamentos da economia (ver W illiamson, 2000 e Frankel, 1999).

${ }^{5}$ Parece um pouco contraditória a idéia de que a alta mobilidade de capitais é que torna desejável a adoção de um regime intermediário. $M$ as, de fato, em um mundo sem mobilidade de capitais, é muito provável que regimes flutuantes se comportem de forma análoga à proposta feita por Friedman (1953). Entretanto, a alta mobilidade de capitais provoca altos desalinhamentos da taxa de câmbio (com seus efeitos sobre a inflação, sobre o balanço de pagamentos e sobre a estrutura de exportações e importações), o que torna desejável a adoção do regime intermediário. A questão relevante passa a ser em que condições tal regime é possível.

${ }^{6}$ Alternativamente, a experiência com regimes intermediários mostra que, quando a taxa se move no interior da banda, a taxa futura normalmente se move menos que a taxa a vista denotando, que 0 mercado espera que a taxa à vista tenda a se reverter ao centro da banda (W illiamson, 2000).
} 
A inda em defesa de regimes intermediários, argumenta-se que estes são capazes de evitar desalinhamentos sem sacrificar objetivos domésticos. Entretanto, é fato que as opções de regimes intermediários já utilizadas, como o crawling peg ou crawling band, não foram capazes de evitar ataques especulativos. ${ }^{7}$ A opção passa a ser buscar estruturas mais flexíveis como a taxa de referência, as margens suaves e as bandas de monitoramento.

$\mathrm{N}$ a proposta da taxa de referência as autoridades não têm obrigação de intervir no mercado de câmbio, mas seu objetivo é conduzir políticas que influenciem a taxa de câmbio de forma a aproximá-la desta taxa. N esta proposta, a defesa do governo jamais induziria uma crise, já quenão existe um comprometimento público em manter qualquer taxa.

$\mathrm{N}$ o caso de margens suaves, a proposta defende que o papel das autoridades seja manter a média móvel da taxa de câmbio no interior de uma banda definida, ao contrário de manter a taxa no interior da banda ao longo de todo o período.

A banda de monitoramento representa uma estimativa oficial e anunciada da taxa de câmbio de equilíbrio. No interior de algum intervalo a autoridade monetária não intervém no mercado. U ma vez que a taxa tenha saído deste intervaIo, poderia haver intervenção, entretanto, a autoridade não tem qualquer comprometimento público em fazê-lo.

Este conjunto de propostas tenta estabelecer estruturas mais flexíveis, cujo objetivo principal seja manter a competitividade de um país sem, no entanto, deixá-lo vulnerável aos ataques especulativos. 0 problema é que em nenhuma destas propostas há um comprometimento oficial com a manutenção de al guma meta para a taxa de câmbio, de forma que não existe transparência na condução da política cambial, o que acarreta divergências na formação de expectativas entre os agentes e oportunidades para a especulação contra a moeda doméstica. ${ }^{8}$

\section{UM A PROPOSTA DE REGIME CAMBIAL}

Propõe-se um regime cambial intermediário capaz de reduzir a presente volatilidade da taxa de câmbio em mercados emergentes. A proposta é baseada no fato de que, em um mundo com alta mobilidade de capitais, a determinação da taxa de câmbio deve ser dada pelo mercado, já que dificilmente um governo consegue ter um volume de reservas necessário para conter um ataque especulativo.

$\checkmark$ ale ressaltar que crises cambiais não são associadas necessariamente a fun-

\footnotetext{
${ }^{7}$ A análise tradicional tem focado os ataques especulativos da última década para justificar a adoção de regimes extremos (flutuante, currency board, união monetária, dolarização plena). Entretanto, é um erro argumentar que estes regimes extremos não são vulneráveis a ataques especulativos. Para uma síntese deste contra-argumento, ver Williamson, 2000; p. 15-18.

${ }^{8}$ A pesar da banda de monitoramento representar um anúncio oficial da taxa de equilíbrio, a autoridade monetária não tem qualquer regra para a intervenção no mercado, o que pode gerar incertezas em relação aos reais objetivos das ações do BC.
} 
damentos frágeis e políticas inconsistentes como costuma-se argumentar (ver, por exemplo, Fischer (1998)). A crise asiática mostrou que políticas consideradas sadias não são suficientes para conter ataques especulativos (ver Furman \& Stiglitz (1998)).

A determinação da taxa de câmbio, no entanto, deve ser validada pelo Banco Central (doravante $B C$ ) com alguma suavidade. 0 objetivo é que, no caso de um choque visto como temporário, a suavidade dada pelo BC seja capaz de minimizar ruídos desnecessários no mercado de câmbio. A lternativamente, no caso de choques permanentes, a alteração da taxa de câmbio será validada pelo BC, com alguma defasagem, sem que os agentes se preocupem se sua atuação estiver defendendo uma taxa inconsistente com o equilíbrio de mercado.

0 regime, então, é baseado em uma média móvel com bandas ajustáveis. Ao início do período t o câmbio é determinado pela média do período t-1 a t- $\eta$. 0 governo estabelece bandas onde a taxa de câmbio pode variar ao longo do período t. Q uando o câmbio atingir a extremidade da banda, o governo intervém no mercado para mantê-lo dentro do intervalo definido. Ao fim do período to câmbio tem seu valor determinado dentro do intervalo estabelecido pelo governo.

$\mathrm{N} o$ início do período $t+1$, o câmbio incorpora o valor que tomou ao fim do período t e exclui o valor do período $t-\eta$. A banda do período $t+1$ se refere a um intervalo que toma como referência a média do câmbio no período (t) a $(t-\eta+1)$. Pondo formalmente, 0 valor do câmbio no início do período $t+1$ será dado por:

$$
y_{t+1}=(1 / \eta) \sum_{i=t-n+1}^{t} y_{i}
$$

As bandas cambiais durante o período $t+1$ são dadas por:

$$
(1-x) \mathrm{y}_{\mathrm{t}+1}<\mathrm{y}_{\mathrm{t}+1}<(1+x) \mathrm{y}_{\mathrm{t}+1}
$$

Uma consequência desta proposta é que para o $B C$ estabelecer formas de manter esta regra, ele deve manter um elevado nível de reservas. A autoridade monetária deve, além disso, levar em consideração seu volume de reservas para determinar as bandas e a própria defasagem com a qual pretende administrar a taxa de câmbio. Q uanto mais comprimida a banda ou quanto mais suavidade 0 $\mathrm{BC}$ deseja impor à trajetória do câmbio (o que se reflete na defasagem imposta sobre o cálculo da média móvel), mais el evado deve ser o volume de reservas necessário para a manutenção do regime. ${ }^{9}$

R essalta-se que, como este tipo de regra é anunciado e o mercado entende 0 seu funcionamento, esta intervenção não deve ser vista, pelo mercado, como uma

\footnotetext{
${ }^{9}$ Este ponto se faz relevante, principalmente, no caso de um ataque especulativo, pois em tal evento a el evada suavidade reduz a flexibilidade do regime, o que torna necessária a manutenção de um nível el evado de reservas. Este ponto no faz retornar ao trade off entre flexibilidade e credibilidade com 0 qual o BC se depara.
} 
tentativa em manter uma taxa de câmbio inconsistente. Pelo contrário, o mercado percebe que esta intervenção nada mais é do que a tentativa de suavização de alguns movimentos temporários ou abruptos. $N$ as outras propostas a tentativa de intervenção pode ser vista como a manutenção de uma taxa inconsistente, já que o mercado não percebe a real intenção do BC, dada a falta de transparência na condução do regime.

A maior vantagem desta proposta é que uma pressão temporária sobre 0 câmbio, que resultará em uma alteração temporária do seu patamar, será suavizada pelo BC. U ma pressão permanente que seja responsável por alterar o patamar do câmbio será validada pelo BC. Entretanto, esta alteração de patamar será validada com alguma defasagem, dada pela variável $\eta$, que indica o grau de inércia na determinação da taxa de câmbio, e pela variável $x$, que determina a banda e, portanto, explicita o grau de variação que o BC está disposto a aceitar em um determinado horizonte de curto prazo. Estas duas possibilidades, choques temporários e choques permanentes, são ilustradas na figura 1.

A figura 1 representa uma simulação e foi construída a partir de valores hipotéticos para a taxa de câmbio. Um choque temporário é definido aqui como um distanciamento de curta duração da taxa de câmbio vigente anteriormente na economia. Um choque permanente altera de forma definitiva o patamar da taxa de câmbio.

É esperado que, com o regime proposto, o câmbio se comporte de maneira mais estável sem perder sua capacidade de resposta que será dada com certa defasagem. A figura 1 mostra que no primeiro caso (choque temporário), o câmbio não atinge o pico e sua evolução não responde a desvios de curtíssimo prazo (região circulada). No segundo caso (choque permanente), o câmbio atinge um novo patamar após um certo período em que o choque se desfez, sem, no entanto, obedecer aos picos de curtíssimo prazo (região circulada).

Este exercício mostra que o regime proposto deve tornar as expectativas mais estáveis, dado que o mercado sabe que é capaz de determinar a taxa de câmbio e que a ação do BC apenas suavizará os desvios de curtíssimo prazo. N este caso, 0 regime é, teoricamente, próximo ao flutuante com a vantagem de que a especulação pode se tornar realmente estabilizadora. ${ }^{10}$

\footnotetext{
${ }^{10}$ Poder-se-ia argumentar que o BC estaria retardando o processo de ajustamento aos choques. Entretanto, é fato que, em choques permanentes sobre a taxa de câmbio, as expectativas se tornam tão instáveis que a taxa de câmbio recorrentemente ultrapassa seu novo patamar de equilíbrio (teoria do overshooting de Dornbusch (1976)). N a linguagem usada no texto, é como se existisse um choque temporário dentro do choque permanente. Esta proposta tem a vantagem de reduzir o impacto deste desvio temporário em relação ao novo patamar, ainda que o impacto desta regra sobre as expectativas fosse nulo.
} 

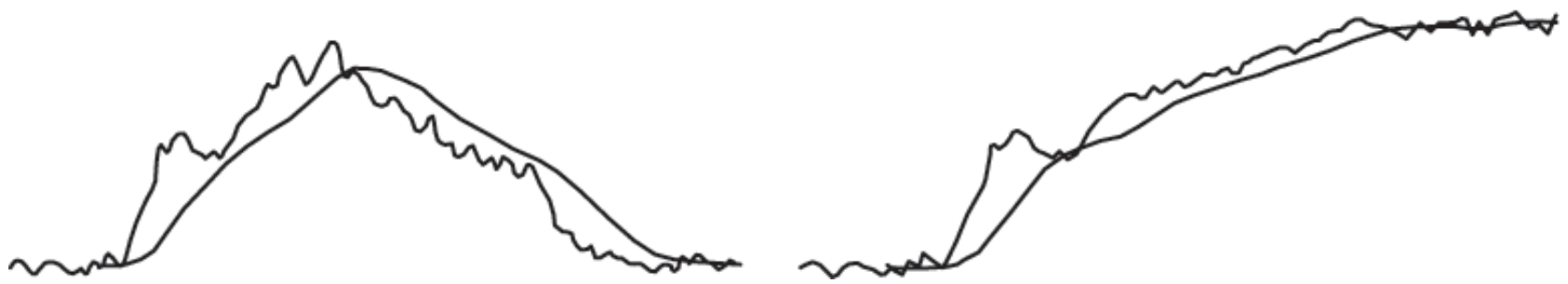

\section{SIM ULAÇÕES PARA O CASO BRASILEIRO}

Com a finalidade de observar o comportamento deste regime realizaram-se algumas simulações para o caso brasileiro. A série foi simulada da seguinte forma: a partir de janeiro de 1999, o Brasil adotou o regime flutuante. Calculou-se a média móvel a partir de maio de 1999, quando as incertezas em relação ao regime cambial já estavam se estabilizando.

Estipulou-se o período de 30 dias úteis para a determinação da média móvel $(\eta=30)$. A nalisou-se, ainda, o comportamento do câmbio para uma banda de $5 \%$ $(x=0,05)$. A série foi simulada de forma que o centro da banda fosse determinado pela média móvel. Q uando os valores efetivos ultrapassavam os limites da banda, estes eram utilizados para o cálculo do câmbio na média móvel (pela regra de que o BC deve intervir nesta situação).

A figura 2, a seguir, mostra a taxa de câmbio flutuante para o Brasil no período de junho de 1999 a junho de 2003. Concomitantemente ao câmbio flutuante, plotaram-se as bandas ajustáveis para avaliar-se como o BC deve-se comportar neste regime. ${ }^{11}$

Esta análise sugere, de acordo com gráfico abaixo, três regiões distintas: (i) a primeira região sugere uma estabilidade em que nenhuma intervenção no mercado de câmbio se faz necessária; ${ }^{12}$ (ii) a segunda sugere uma tendência ascenden-

\footnotetext{
* A média móvel foi simulada para 12 períodos. Fonte: elaborada pelo autor.

${ }^{11}$ Vale ressaltar que supõe-se, para a análise, que o comportamento do mercado de câmbio esteja dado. Evidentemente, esta análise está sujeita à crítica de que o comportamento do mercado de câmbio deve-se alterar, dado que as regras mudaram. Entretanto, o exercício permanece válido já que o objetivo é avaliar o comportamento do regime diante de choques na economia real.

${ }^{12} \mathrm{~A}$ análise desta seção é baseada no comportamento do câmbio sob o regime flutuante. Q uando este tipo de afirmação for feita, deve-se entender que nenhuma intervenção, além das realizadas durante o período em questão, se faz necessária.
} 
te da taxa de câmbio onde algumas intervenções seriam necessárias; e (iii) a terceira com alta volatilidade em que as intervenções devem ser sistemáticas. ${ }^{13}$

Figura 2: Taxa de câmbio flutuante e bandas ajustáveis - Brasil março de 1999 a abril de 2003

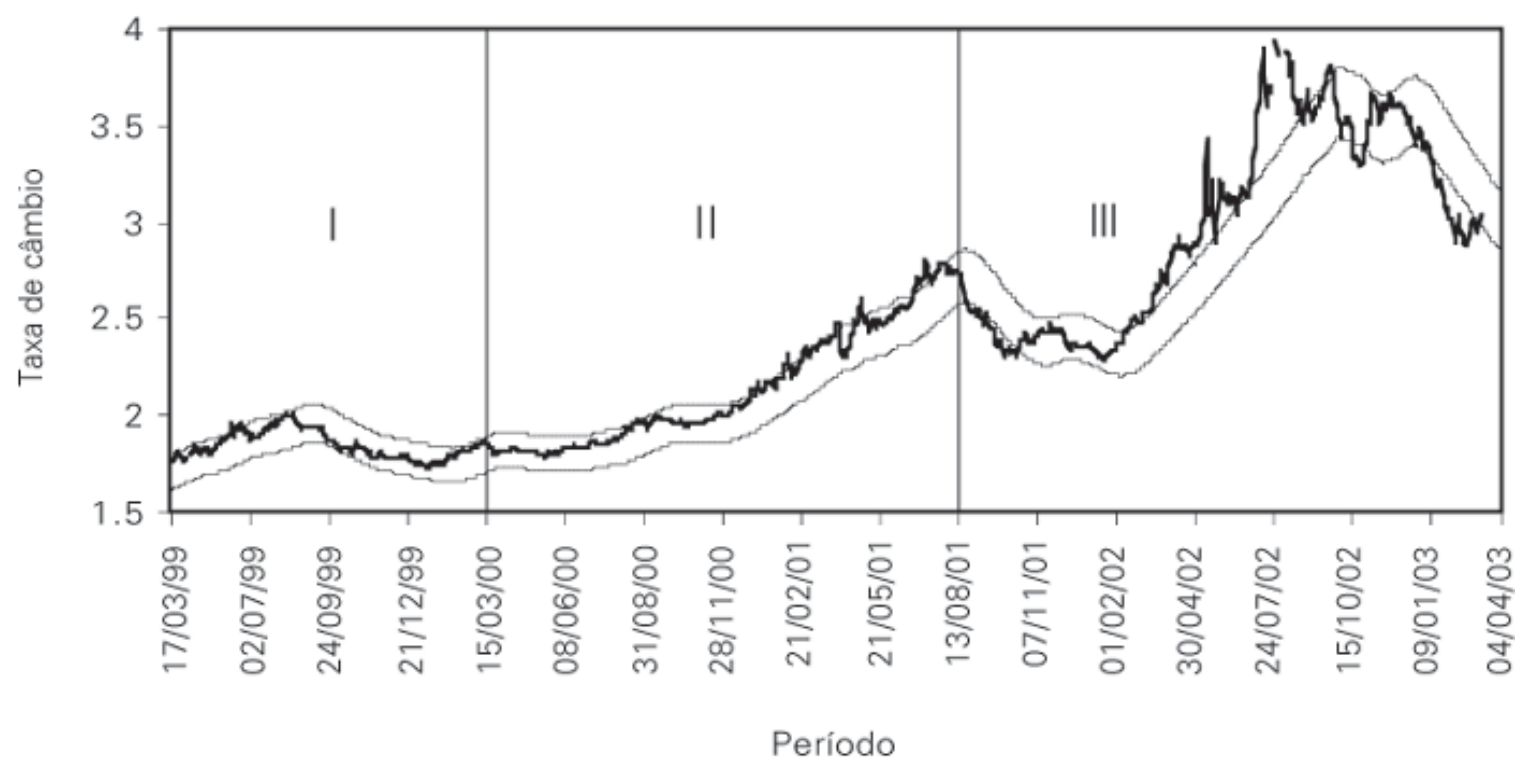

Fonte: Elaborado pelo autor com base nos dados disponíveis pelo Banco Central.

A análise da figura 2 mostra que a região III deve ser considerada uma região crítica. N esta região, que cobre o período de agosto de 2001 até abril de 2003 seriam necessárias 137 intervenções no teto da banda e 95 intervenções no piso da banda. As intervenções no piso se comportaram de forma interessante. D urante 0 ano de 2003 (até junho) seriam realizadas 56 intervenções para defender o piso e durante 0 ano de 2002 apenas três intervenções deveriam ser realizadas.

Alternativamente, durante 0 ano de 2002 seriam realizadas 122 intervenções para proteger o teto da banda. Esta análise sugere que dificilmente o BC conseguiria manter esta regra para o câmbio durante 0 ano em questão. Isto nos leva à necessidade de analisar mecanismos complementares ao regime cambial: os controles de capitais e cláusulas de escape.

D eve-se analisar, ainda, a questão da volatilidade cambial. $\mathrm{N}$ a figura 3 , mostra-se o comportamento do valor absoluto da diferença da taxa de câmbio. Como era de se esperar, existe grande discrepância em favor do regime de médias móveis. Conclui-se daí, que o objetivo principal da proposta, que é o de reduzir a volatilidade cambial, seria atingido.

${ }^{13}$ Uma opção para a análise seria aumentar as bandas para, por exemplo, 10\%. Entretanto, é difícil acreditar que as conclusões seriam muito diferentes. Além disso, a necessidade de uma banda excessivamente larga pode acabar por absorver flutuações excessivas, que é exatamente o que a proposta pretende evitar. 
Figura 3 - Variação do câmbio em valor absoluto - Brasil jun/1999 a jun/2003
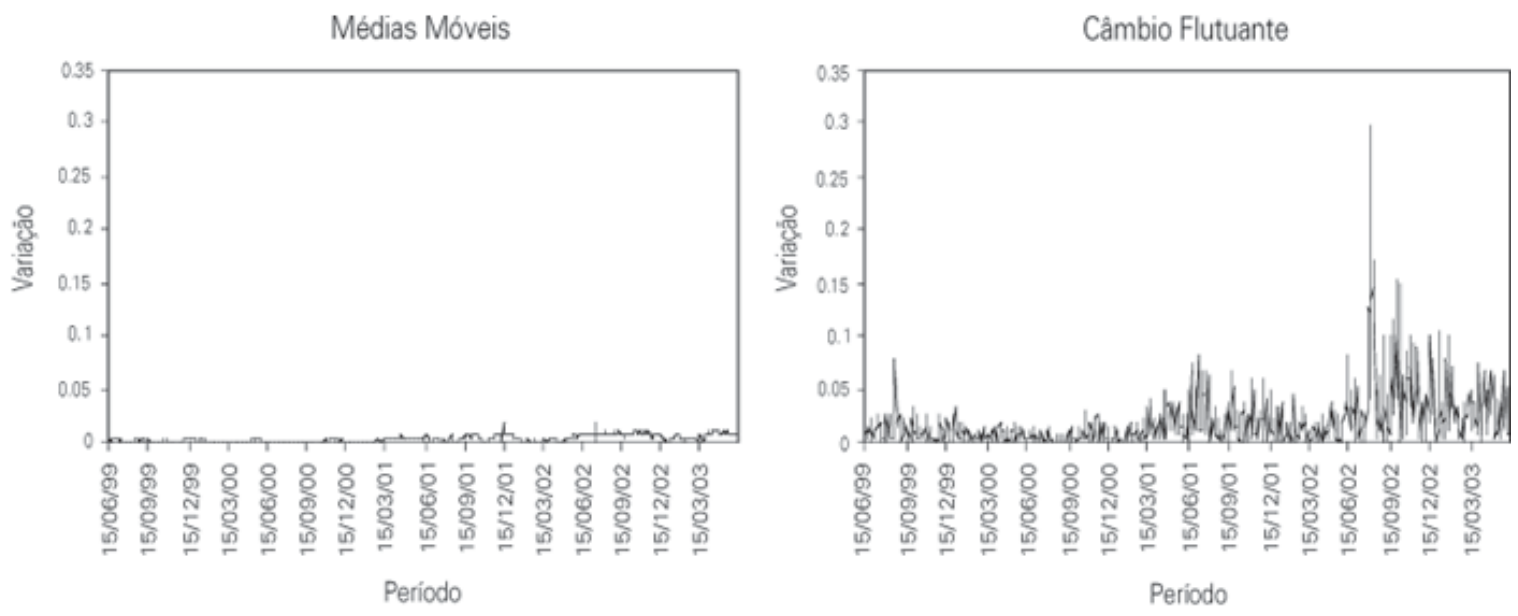

Fonte: Elaborado pelo autor com base nos dados disponíveis pelo Banco Central do Brasil.

\section{SOBRE A NECESSIDADE DE CONTROLES DE CAPITAISE/OU CLÁUSULAS DE ESCAPE}

A análise anterior mostrou a necessidade do regime proposto ser complementado por outras ações. Tais ações têm sido amplamente discutidas, dados os ataques especulativos que recorrentemente têm atingido as economias. U ma possibilidade é a intervenção no mercado de câmbio via controle de capitais. Em especial, as discussões giram em torno de sua eficácia e desejabilidade sobre a alocação de recursos. ${ }^{14}$

R ecentemente, em uma série de artigos publicados nesta revista, tem-se tentado discutir o papel da liberalização da conta de capital no Brasil. Arida (2003a e 2003b) defendeu a liberalização na conta de capital argumentando que existe uma relação entre a incerteza quanto à possível adoção de controles de capitais no futuro e o risco. Esta incerteza poderia elevar a percepção de risco, o que resultaria na elevada taxa de juros interna observada no Brasil. A elevada taxa interna de juros limita a política fiscal que tem que adotar elevados superávits primários. Arida (2003a) conclui, então, que a conversibilidade poderia reduzir a taxa de juros e o superávit primário.

0 problema com a argumentação desse autor é que, do ponto de vista empírico, pode-se dizer que o argumento não se sustenta. Existem evidências de que tanto a política fiscal quanto a política monetária se tornam mais restritivas ao liberalizar a conta de capital. ${ }^{15} \mathrm{~A}$ s evidências brasileiras também não confirmam a hipótese de que controles de capitais tenham impactos significativos sobre a percepção de risco dos agentes (O reiro, Paula \& Silva, 2004).

\footnotetext{
${ }^{14}$ Para uma discussão sobre a eficácia e a desejabilidade de controle de capitais ver Rodrik (1998), Fischer (1998) e Eichengreen, Tobin \& Wyplosz (1995).

${ }^{15}$ Para a política fiscal ver Kim (2003) e para a política monetária ver Gruben \& M cLeod (2002).
} 
No caso brasileiro tem ocorrido exatamente o contrário. Conforme diagnosticaram O reiro, Paula \& Silva (2003), a liberalização da conta de capital tem, entre outras coisas, reduzido a autonomia na condução da política monetária e aumentado a fragilidade externa da economia por meio de sucessivas crises cambiais. Sobre esta segunda característica, Sicsú (2002) mostrou que o excesso de volatilidade no mercado de câmbio brasileiro eleva a tendência da taxa de câmbio, o que o fez argumentar em defesa dos controles de capitais. ${ }^{16}$

A ssim, em uma situação de fuga de capitais ou de um influxo excessivo que pode apreciar demasiadamente a taxa de câmbio e comprometer a estratégia comercial do país, a adoção de controles de capitais se configura como uma alternativa importante para a estabilidade macroeconômica.

A figura 4 ilustra como se espera que a taxa de câmbio se comporte com a imposição de controles de capitais. Ela foi construída extrapolando o comportamento da regra para o futuro (ou seja, com a imposição de controles de capitais a autoridade monetária consegue manter a regra) e incluindo a hipótese de que a autoridade monetária administre com metas para a taxa de câmbio.

Esta figura mostra que após a introdução de controles de capitais, a série permanece suave e os pequenos sobressaltos (que estão circulados na figura) são oriundos de ajustes na meta por parte das autoridades monetárias (os valores utilizados para as metas foram 3,00 para 2001, 3,10 para 2002 e 3,20 para 2003). A ssim, o país conseguiria, além de estabilizar a taxa de câmbio, manter uma política de exportações ativa. R essalta-se o caráter ilustrativo da figura 3 que objetiva tão somente sugerir uma possível trajetória para a taxa de câmbio, dentre várias possíveis, dado que é difícil estabelecer critérios objetivos para esta análise.

Sobre a possibilidade de manter uma taxa de câmbio desvalorizada para incentivar as exportações, deve-se considerar seu impacto sobre o elevado endividamento externo brasileiro (privado e público), o que pode inviabilizar investimentos. Entretanto, com a adoção de controles de capitais e a possibilidade de redução do superávit primário, podem ser realizados investimentos públicos com o objetivo de promover as exportações.

U ma alternativa à proposta de controle de capitais seria a adoção de cláusulas de escape, uma solução análoga à do regime de inflation targeting. Com esta opção, o BC poderia abrir mão da regra quando a pressão do mercado de câmbio atingisse um certo patamar ou quando as reservas atingissem um piso preestabelecido e, após a crise, o BC se comprometeria manter da antiga regra.

Como o objetivo da proposta é a suavização da taxa de câmbio, a introdução de cláusulas de escape deveria ser imposta em situações em que o abandono da regra não prejudicasse a suavidade da série. Por exemplo, no caso de uma pressão que valorizasse em demasia o câmbio, o BC poderia abrir mão da regra

\footnotetext{
${ }^{16}$ Em um recente estudo, Tamirisa (2004) encontrou evidências de que adoção de restrições à saída de capitais na crise da M alásia conseguiu reduzir a taxa de juros enquanto que a adoção de restrições à entrada elevou a taxa de juros.
} 
Figura 4: Evolução da taxa de câmbio e introdução de controle de capitais

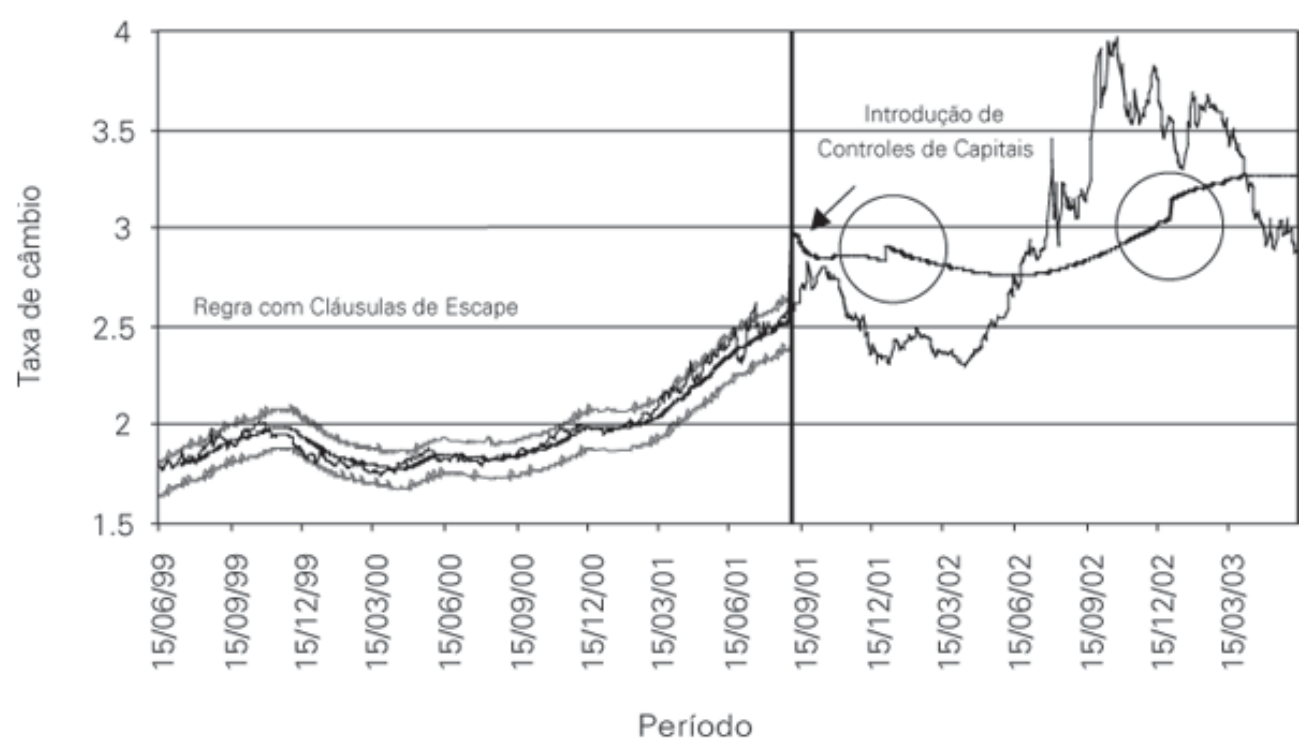

para manter a competitividade externa da economia realizando intervenções esterilizadas. Assim, cláusulas de escape poderiam ser empregadas na medida em que outros objetivos da política econômica estivessem comprometidos, não se constituindo, então, em uma alternativa equivalente aos controles de capitais.

A proposta de introdução de cláusulas de escape é baseada na experiência internacional com os países emergentes que sofreram ataques especulativos. Estes países apresentaram grandes saltos na taxa de câmbio durante os ataques. Entretanto, após essas crises, a taxa de câmbio retomou uma trajetória estável conforme a figura $5 .{ }^{17}$

Figura 5 - Evolução do câmbio em países emergentes selecionados

México - jan/90 a dez/02

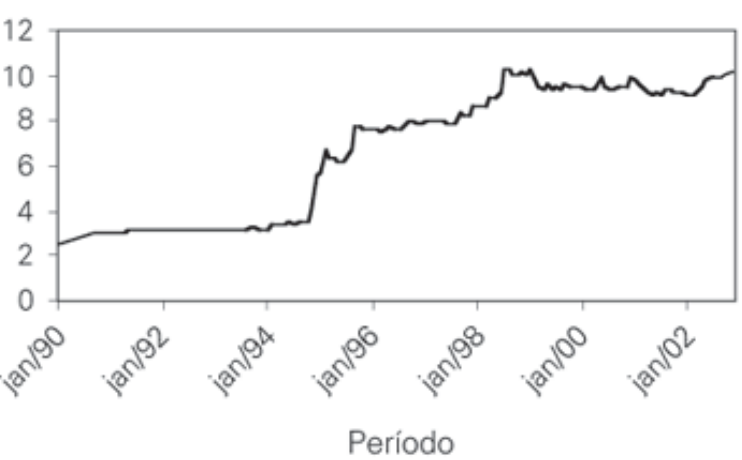

Coréia do Sul - jan/94 a dez/02

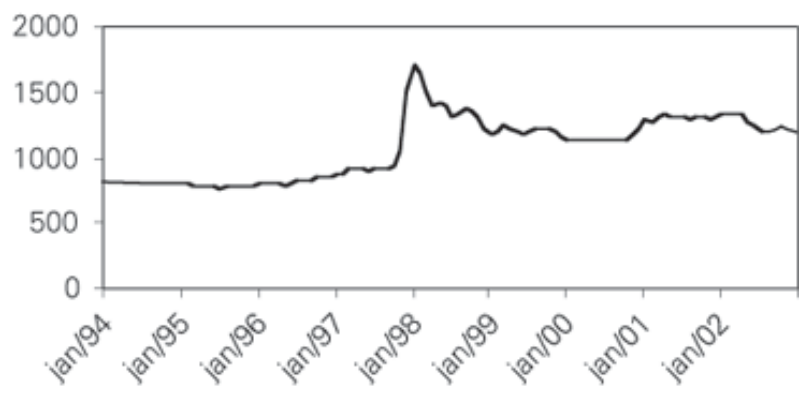

Período

Fonte: Elaborado pelo autor com base nos dados disponíveis pelos Bancos Centrais dos países analisados

${ }^{17} \mathrm{~A}$ proposta de Williamson inclui, além do abandono temporário do regime, algum direito internacionalmente sancionado para suspender o serviço da dívida até que a normalidade seja restaurada (2000, p. 28). 
O ponto relevante para a análise, no caso, é que estes países têm capacidade para manter alguma regra de determinação para a taxa de câmbio passado os ef eitos de choques. Esta análise independe do regime cambial utilizado pós-crise. 0 fato é que, independentemente do regime, o câmbio assume, novamente, uma trajetória passível de seguir uma regra.

\section{CONCLUSÕES}

Este trabalho mostrou a necessidade de alternativas aos regimes extremos. Para suprir tal necessidade, propôs-se um regime intermediário alternativo. 0 regime baseia-se em uma média móvel com bandas ajustáveis. A principal vantagem deste regime em relação às propostas atuais é o papel da transparência. Espera-se que um comprometimento público com este regime torne as expectativas, de fato, estabilizadoras evitando o excesso de volatilidade no mercado de câmbio.

A análise desta proposta para o caso brasileiro levou-nos concluir que existem situações em que sua credibilidade pode ser posta em cheque, o que nos fez discutir a necessidade de mecanismos complementares ao regime cambial. U ma possibilidade é a adoção de controles de capitais. A experiência brasileira recente de liberalização na conta de capital tem mostrado uma volatilidade excessiva no mercado de câmbio que poderia ser reduzida adotando-se esta estratégia.

A segunda possibilidade é a adoção das cláusulas de escape que foram analisadas à luz da experiência internacional em situações pós-crise e devem ser determinadas em duas direções: (i) o comprometimento de um piso para as reservas e (ii) o comprometimento de uma taxa de câmbio real mínima. 0 comprometimento público destas medidas e o esclarecimento de seus objetivos é importante na medida em que os agentes possam formar expectativas convergentes.

Conclui-se daí que, apesar da necessidade de estruturas intermediárias e flexíveis, mecanismos complementares devem ser utilizados para tornar estas estruturas críveis e evitar ou minimizar os impactos de ataques especulativos. Entretanto, em um mundo com el evada mobilidade de capitais não se deve descartar 0 papel da transparência como um aspecto permanente da política cambial na medida em que pode tornar as expectativas mais estáveis.

\section{REFERÊN CIASBIBLIOGRÁFICAS}

ARIDA, P. (2003a). "Ainda sobre a Conversibilidade". Revista de E conomia Política. Vol. 23, no 3, julho-setembro, p. 135-142.

ARID A, P. (2003b). "Por uma M oeda Plenamente Conversível" Revista de Economia Política. Vol. 23, no 3, julho-setembro, p. 151-154.

D OR N BUSCH , R. (1976). "Expectations and Exchange Rate Dynamics" . J ournal of Political Economy. Vol. 84, no 6, December, p. 1.161-1.176.

DOR N BUSCH, R. (1998) "Capital Controls: An Idea Whose Time is Past" . In: Kenen, P. (ed), Should 
the IM F pursue Capital Account Convertibility? Princeton Essays in International Finance, no 207. Princeton University Press.

EICHEN GREEN , B. (1994) "International M onetary Arrangements for the 21st Century." Washington, D.C.: The Brookings Institution.

EICHEN GREEN , B; TOBIN , J. \& WY PLOSZ, C. (1995) "T wo Cases for Sand in the Wheels of International Finance". The E conomic J ournal. V ol. 105, no 428, January, p. 162-172.

FISCHER, S. (1998) "Capital-Account Liberalization and the role of the IM F". In: P. Kenen (ed.), Should the IM F pursue Capital A ccount Convertibility? Princeton Essays in I nternational Finance, $n=207$. Princeton University Press.

FRAN KEL, J. A . (1999) "N o Single Currency Regime is Right for All Countries at All Times". N BER working paper series $n-7338$. September.

FRIED M AN , M . (1953) "The Case for Flexible Exchange Rates". Essays in Positive E conomics. The University of Chicago Press.

FURM AN , J. \& STIGLITZ, J. E. (1998). "Economic Crises: Evidence and Insights from East A sia". Brookings Papers on Economic Activity 2.

GRUBEN , W. \& M CLEOD, D. (2002). "Capital Account Liberalization and Inflation". Economic L etters. Vol. 77, no 2, p. 221-225.

KIM , W. (2003). "Does Capital Account Liberalization Discipline Budget D eficit?" Review of International Economics. Vol. 11, no 5. N ovember.

OREIRO, J. L., PAULA, L. F. de \& SILVA, G. J. C. da (2003). "Fluxos e Controle de Capitais no Brasil: A valiação e Proposição de Políticas". In: Sicsú, J., O reiro, J. L., Paula, L. F. de (org.). A genda Brasil: Políticas E conômicas para o Crescimento com Estabilidade de Preços. Barueri/SP: Editora $M$ anole.

OREIRO, J. L., PAULA, L. F. de \& SILVA, G. J. C. da (2004). "Por uma M oeda Parcialmente Conversível: U ma Crítica a Arida e Bacha". R evista de E conomia Política. Vol. 24, no 2, abril-junho, p. 223-237.

REIN H ART, C. M . (2000) "The M irage of Floating Exchange R ates". The A merican E conomic Review. Vol. 90, no 2, M ay, p. 65-70.

RO DRIK, D. (1998) "W ho N eeds Capital Account Convertibility?". Princeton Essays in International Finance, $\mathrm{n}$-207. Princeton University Press.

SIC SÚ, J. (2002). "Volatilidade Cambial e Taxa de Juros no Brasil". R evista de E conomia Política. Vol. 22, no 3, julho-setembro, p. 132-137.

TAM IRISA, N . (2004). "D o M acroeconomic Effects of Capital Controls Vary by Their Type? Evidence from M alaysia". I M F working paper 04/3. January.

WILLIAM SO N , J. (2000) "Exchange R ate R egimes for Emerging M arkets: Reviving the Intermediate 0 ption". Policy A nalyses in International E conomics 60. September. Institute for International Economics. Washington, DC. 